\title{
Overflow of cold water across the Iceland-Faroe Ridge through the Western Valley
}

\author{
Bogi Hansen ${ }^{1}$, Karin Margretha Húsgarð Larsen ${ }^{1}$, Steffen Malskær Olsen ${ }^{2}$, Detlef Quadfasel ${ }^{3}$, Kerstin Jochumsen ${ }^{3}$, \\ and Svein Østerhus ${ }^{4}$ \\ ${ }^{1}$ Faroe Marine Research Institute, P.O. Box 3051, 110 Tórshavn, Faroe Islands \\ ${ }^{2}$ Danish Meteorological Institute, Lyngbyvej 100, 2100 Copenhagen, Denmark \\ ${ }^{3}$ University of Hamburg, Bundesstrasse 53, 20146 Hamburg, Germany \\ ${ }^{4}$ Uni Research Climate, Nygårdsgata 112, 5008 Bergen, Norway
}

Correspondence: Bogi Hansen (bogihan@hav.fo)

Received: 31 March 2018 - Discussion started: 16 April 2018

Revised: 25 July 2018 - Accepted: 27 July 2018 - Published: 27 August 2018

\begin{abstract}
The Iceland-Faroe Ridge (IFR) is considered to be the third most important passage for dense overflow water from the Nordic Seas feeding into the lower limb of the Atlantic Meridional Overturning Circulation with a volume transport on the order of $1 \mathrm{~Sv}\left(10^{6} \mathrm{~m}^{3} \mathrm{~s}^{-1}\right)$. The Western Valley, which is the northernmost deep passage across the IFR, has been presumed to supply a strong and persistent overflow (WV-overflow), contributing a large fraction of the total overflow across the IFR. However, prolonged measurements of this transport are so far missing. In order to quantify the flow by direct measurements, three instrumental packages were deployed close to the sill of the Western Valley for 278 days (2016-2017) including an acoustic Doppler current profiler at the expected location of the overflow core. The average volume transport of $\mathrm{WV}$-overflow during this field experiment was found to be $(0.02 \pm 0.05) \mathrm{Sv}$. Aided by the observations and a two-layer hydraulic model, we argue that the reason for this low value is the inflow of warm Atlantic water to the Norwegian Sea in the upper layers suppressing the deep overflow. The link between deep and surface flows explains an observed relationship between overflow and sea level slope as measured by satellite altimetry. This relationship, combined with historical hydrographic measurements, allows us to conclude that the volume transport of WV-overflow most likely has been less than $0.1 \mathrm{~Sv}$ on average since the beginning of regular satellite altimetry in 1993 . Our new direct measurements do not allow us to present an updated estimate of the total overflow across the IFR, but they indicate that it may well be considerably less than $1 \mathrm{~Sv}$.
\end{abstract}

\section{Introduction}

Overflow of cold, dense water from the Nordic Seas across the Greenland-Scotland Ridge (Fig. 1) has long been recognized as an important component of the world ocean circulation (Saunders, 2001). Together with water entrained after crossing the ridge, it forms the main component of North Atlantic Deep Water (Dickson and Brown, 1994; Hansen et al., 2004), the deep limb of the Atlantic Meridional Overturning Circulation (AMOC). By transporting carbon dioxide (Sabine et al., 2004) and heat (Hansen et al., 2016) from the atmosphere into the deep ocean, the overflow is also an important component of the climate system.

The Iceland-Faroe Ridge (IFR) is the central part of the Greenland-Scotland Ridge and it separates the deep parts of the Norwegian Sea from the Iceland Basin and the rest of the Atlantic Ocean (Figs. 1 and 2a). The occurrence of overflow across the IFR, "IFR-overflow", was recognized more than a century ago (Knudsen, 1898) and there is a long history of research on the topic as reviewed by Hansen and Østerhus (2000). These studies have demonstrated that overflow occurs in many locations along the IFR and cold, dense water is found in the bottom layer all along the crest of the ridge, as exemplified in Fig. 2b.

Overflow is, however, not the only flow to cross the ridge. Except for the region close to Iceland, most of the water column above the bottom layer over the IFR is dominated by warm water (Fig. 2b) originating farther south in the Atlantic Ocean and flowing into the Norwegian Sea. Strictly speaking, the whole region (including the Norwegian Sea) is part 


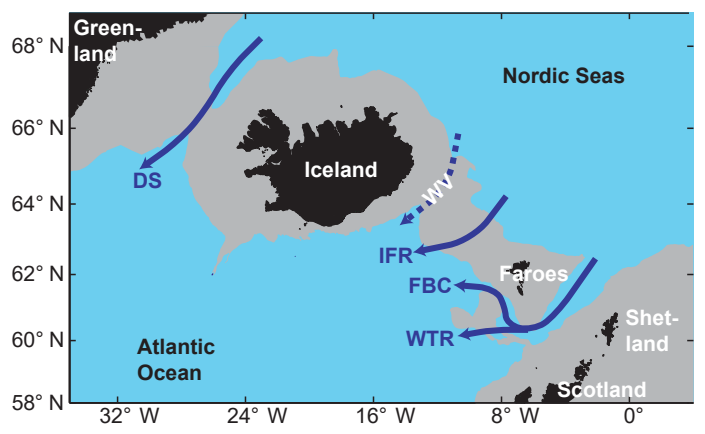

Figure 1. The Greenland-Scotland region (grey areas are shallower than $750 \mathrm{~m}$ ) with the four traditional overflow branches indicated by blue arrows that pass through the Denmark Strait (DS), through the Faroe Bank Channel (FBC), across the Wyville Thomson Ridge (WTR) and across the Iceland-Faroe Ridge (IFR). The focus of this study is on the overflow through the Western Valley (WV) indicated by a hatched blue arrow, which is a component of IFR-overflow.

of the Atlantic Ocean but we will adopt the common practice in studies of this region of reserving the term "Atlantic" for the region southwest of the ridge and use the term "Atlantic water" for this warm water.

According to the float experiment by Rossby et al. (2009), the inflow of Atlantic water, "Atlantic inflow", across the IFR may occur in many locations, but mainly close to the two ends of the ridge, which is consistent with a map of the mean dynamic topography for the region (Fig. 3). The barotropic footprint of the Atlantic inflow therefore has to be taken into account when considering the forcing of IFR-overflow.

For the two main overflow branches from the Nordic Seas that pass through the Denmark Strait and the Faroe Bank Channel (Fig. 1), respectively, observational efforts have resulted in strong constraints on their volume transport (Jochumsen et al., 2017; Hansen et al., 2016). In contrast, the long history of research on IFR-overflow has not resulted in a well-constrained estimate of its volume transport. Based on the first overflow expedition (Overflow '60), coordinated within the International Council for the Exploration of the Seas (Hermann, 1967), IFR-overflow has been considered to be around $1 \mathrm{~Sv}\left(1 \mathrm{~Sv}=10^{6} \mathrm{~m}^{3} \mathrm{~s}^{-1}\right)$ in recent literature (e.g. Olsen et al., 2016). This transport estimate was supported by Perkins et al. (1998) who reported an overflow of at least $0.7 \mathrm{~Sv}$. It is also consistent with the estimate from a comprehensive autonomous glider experiment (20062009), which gave a lower bound of $0.8 \mathrm{~Sv}$ for the total IFRoverflow (Beaird et al., 2013).

The crest of the IFR is deepest close to the Faroe Islands (Fig. 2b), but direct current measurements from the three acoustic Doppler current profiler (ADCP) moorings reported by Østerhus et al. (2008) did not show strong overflow in that region, and Beaird et al. (2013) estimated only $0.3 \mathrm{~Sv}$ to cross over the southeastern half of the ridge. Instead, most reports of strong overflow are from the part close to Iceland (Perkins et al., 1998; Voet, 2010; Olsen et al., 2016), and Beaird et al. (2013) estimate that the overflow across the northwesternmost part of the ridge is at least $0.5 \mathrm{~Sv}$.

The northwesternmost passage across the IFR is the Western Valley (WV, Figs. 1 and 2), and the overflow through this passage, "WV-overflow", is the focus of this study. The WV is the deepest passage across this part of the IFR (Fig. 2) and there are at least two good arguments for expecting a strong and persistent WV-overflow. The first argument is theoretical and based on analogy with other overflow sites. Most studies suggest that the deep and intermediate water in this part of the Nordic Seas generally has a cyclonic circulation (Nøst and Isachsen, 2003; Søiland et al., 2008; Voet, 2010) as does the surface layer (Perkins et al., 1998; Jakobsen et al., 2003; Koszalka et al., 2011). The upstream source for overflow through the WV would then be located east of Iceland where dense water reaches close to the surface (e.g. Fig. 6 in Olsen et al., 2016). Simple overflow models that have been successful elsewhere (e.g. Whitehead, 1998) then imply a WV-overflow exceeding $1 \mathrm{~Sv}$ in volume transport. This overflow would be expected to flow along the Icelandic slope and to cover the deep parts of the WV especially over its Icelandic flank. These assumptions are in agreement with the cold water of overflow character that is typically seen in this region on sections following the ridge crest as exemplified in Fig. 2b.

The second argument is based on moored current measurements downstream of the WV. Perkins et al. (1998) observed a strong (approximately $50 \mathrm{~cm} \mathrm{~s}^{-1}$ core speed) and persistent bottom current at a site about $90 \mathrm{~km}$ downstream of the WV sill and roughly $200 \mathrm{~m}$ deeper (blue circle labelled "P" in Fig. 2a), which they estimated to transport at least $0.7 \mathrm{~Sv}$ of Arctic intermediate water, i.e. "pure overflow". The persistence of this current was confirmed by an ADCP, deployed for more than 2 years at almost the same location (Voet, 2010; Olsen et al., 2016). Beaird et al. (2013) have argued that this bottom current can only derive from overflow across the northwestern part of the IFR where the WV is the deepest passage.

Observations made in the WV itself are, however, more ambiguous than the evidence from the downstream measurements. Thus, Perkins et al. (1998) also had moorings closer to the sill of the WV and they "find no evidence for significant flow through the WV". Likewise, Beaird et al. (2013) found that "the overflow transport in the WV is more variable than the current meter records of Perkins et al. (1998) suggest" where they presumably refer to the downstream measurements at site P. This discrepancy was the main motivation for our field experiment, in which we placed three moorings along a section across the $\mathrm{WV}$ close to the sill (red rectangle in Fig. 2a). The instrumentation was deployed in August 2016 and all the data were successfully recovered in May 2017. With the chosen configuration of measurements close to the bottom, we hoped to catch any overflow that 

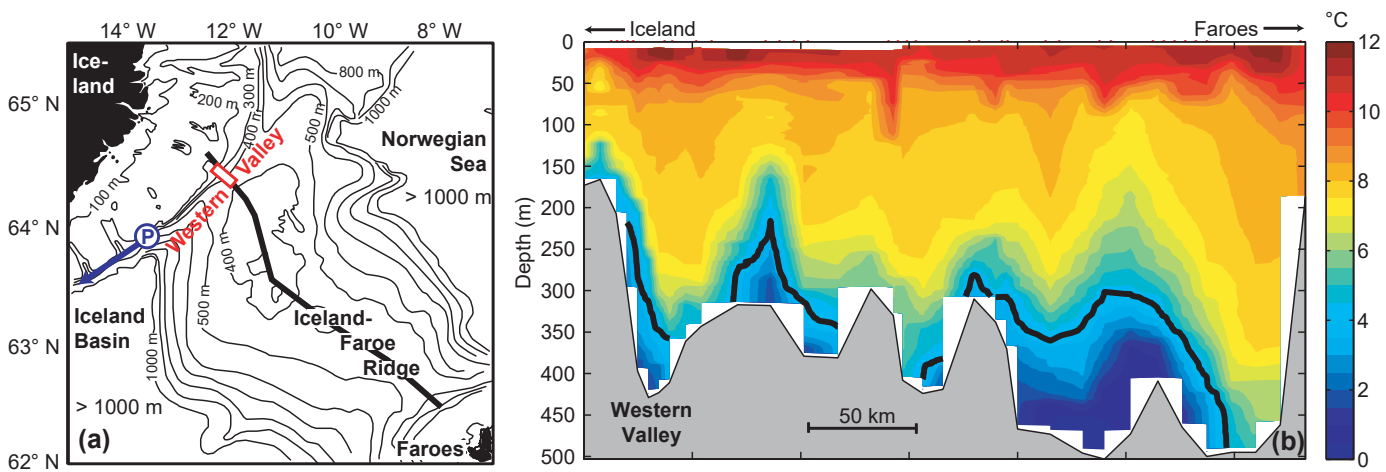

Figure 2. (a) Bottom topography of the Iceland-Faroe Ridge with isobaths for every $100 \mathrm{~m}$ down to $1000 \mathrm{~m}$ depth. The red rectangle in the Western Valley indicates the instrument deployment sites of our field experiment. The blue circle marks site $\mathrm{P}$ and the blue arrow indicates the strong and persistent bottom current at this site reported in previous studies. The thick black line along the ridge crest indicates a conductivity-temperature-depth (CTD) section occupied by R/V Poseidon in August 2016. (b) The potential temperature distribution along that section is shown as background colour with the black line indicating the $\sigma_{\theta}=27.8 \mathrm{~kg} \mathrm{~m}^{-3}$ isopycnal, commonly used as the upper boundary of the overflow layer.

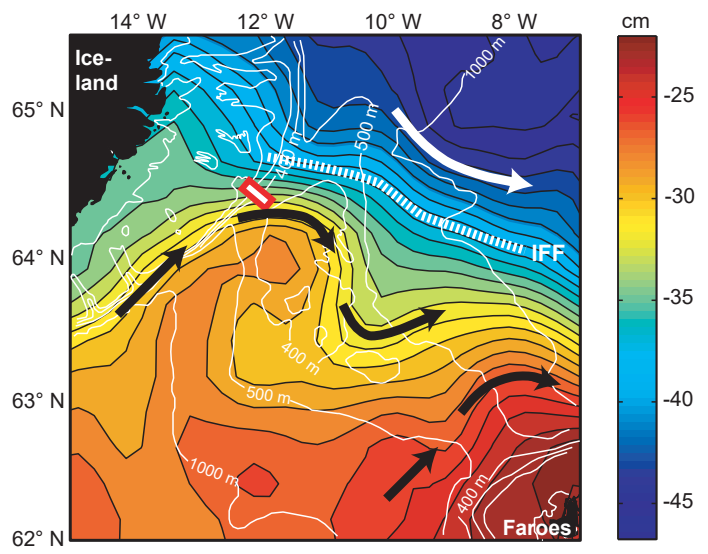

Figure 3. The mean dynamic topography (background colours) above the IFR according to altimetry data from the Copernicus Marine Environment Monitoring Service (CMEMS) (Sect. 2.3). Isobaths are shown by thin white lines for every $100 \mathrm{~m}$ down to $500 \mathrm{~m}$ and for $1000 \mathrm{~m}$ depth. Black arrows indicate the two main Atlantic inflow regions over the IFR. The white arrow indicates the surface circulation of the Norwegian Sea. The thick hatched white line indicates the Iceland-Faroe Front (IFF). The red rectangle marks the deployment sites of our field experiment.

might have bypassed the moorings of Perkins et al. (1998) in the WV. The experiment was also designed to test a lowcost system for long-term monitoring of WV-overflow.

In the following, we first describe the materials and methods used and the results from the field experiment. In order to get a longer-term perspective, we compare our results with sea level variations measured by satellite altimetry and with historical hydrographic observations. From the results, we can derive estimates of the average volume transport of WVoverflow both for the duration of the field experiment and
Table 1. Positions and bottom depths of the three deployment sites. BTL indicates the bottom temperature logger. All instruments were placed directly on the bottom in trawl-protected frames.

\begin{tabular}{llccc}
\hline Site & Instruments & Latitude & Longitude & Depth \\
\hline A & BTL & $64.477^{\circ} \mathrm{N}$ & $12.139^{\circ} \mathrm{W}$ & $297 \mathrm{~m}$ \\
B & ADCP + MicroCAT & $64.445^{\circ} \mathrm{N}$ & $12.063^{\circ} \mathrm{W}$ & $402 \mathrm{~m}$ \\
$\mathrm{C}$ & BTL & $64.401^{\circ} \mathrm{N}$ & $11.967^{\circ} \mathrm{W}$ & $433 \mathrm{~m}$ \\
\hline
\end{tabular}

for longer periods, and we discuss the validity of these estimates. Consistent with the results of Perkins et al. (1998), we find WV-overflow to be much weaker than might be expected from the arguments presented above, and we try to explain why that is the case using the results from a twolayer hydraulic model. Finally, we discuss the implications of our results and present our conclusions and perspectives. In order to keep the presentation more coherent, some of the details have been placed in the accompanying Supplement, which also includes a more detailed description of the hydraulic two-layer model invoked in the discussion.

\section{Material and methods}

The main results in this study are based on a field experiment including the deployment of moored instrumentation at three locations in the WV (Table 1). To help interpret these data, we include also hydrographic observations from recent and historical CTD profiles in the region as well as sea level variations from satellite altimetry. 


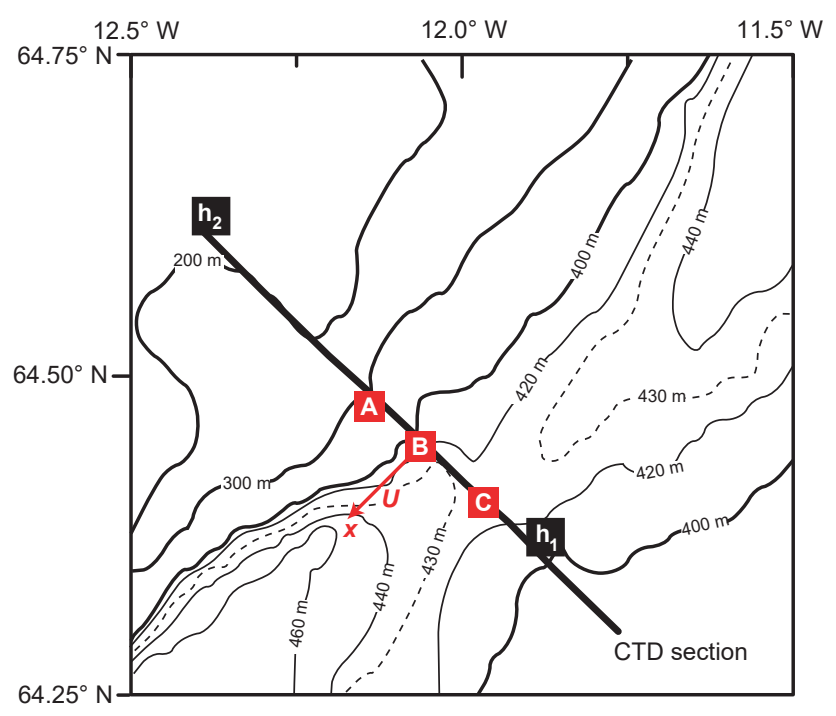

Figure 4. The region around the Western Valley with bottom topography based on ETOPO1. The positions of the three moorings of the field experiment are marked by red squares. Black squares indicate the two selected altimetry grid points. The thick black line shows a CTD section that was occupied by R/V Poseidon during the deployment cruise in August 2016 and by R/V Magnus Heinason during the recovery cruise in May 2017. The red arrow indicates the chosen $x$ direction for along-valley flow towards the Atlantic $\left(225^{\circ}\right)$ with velocity component labelled $U$.

\subsection{The field experiment (2016-2017)}

The three deployment sites were labelled A-C (Fig. 4). At sites A and C, each package contained a SeaBird SBE39 temperature recorder and battery packs attached to a LinkQuest acoustic modem enclosed in a specially developed trawlproof frame mounted on the bottom (Fig. S1, right panel, in the Supplement). Each of these bottom temperature loggers (BTLs) recorded the bottom temperature at hourly intervals, which could be uploaded acoustically to a vessel.

At site B, a $150 \mathrm{kHz}$ RDI Broadband ADCP and a SeaBird MicroCAT (SBE37) temperature and salinity logger were deployed within a trawl-proof frame (Fig. S1, left panel) that was attached by two acoustic releases to a concrete block mounted on the bottom. The MicroCAT recorded bottom temperature, conductivity and pressure at $10 \mathrm{~min}$ intervals. The ADCP recorded velocity at 30 levels (bins) with $10 \mathrm{~m}$ vertical resolution every $20 \mathrm{~min}$.

The experimental design was based both on theoretical arguments and on historical hydrographic sections crossing the WV. With the chosen locations, we expected sites A and C to be close to the boundaries of the overflow plume passing through the valley. The measured bottom temperatures at these two sites would then document variations in these boundaries, i.e. the position of the plume in the valley. Likewise, the ADCP at site B was located where we expected the thickest overflow layer and the core of the plume (Fig. 5).

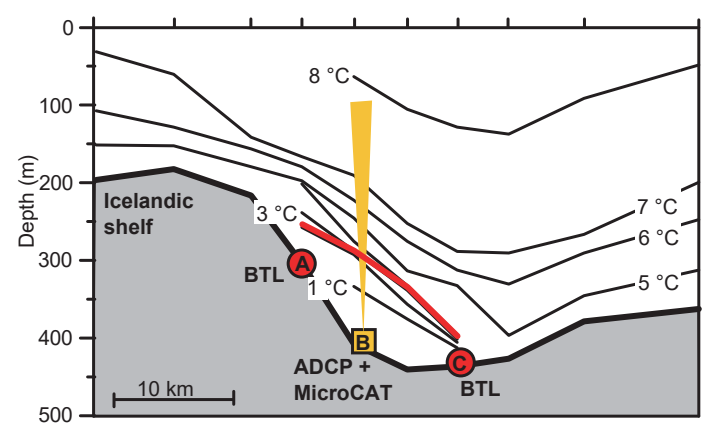

Figure 5. Section through the three moorings of the field experiment (Fig. 4, thick black line). The yellow square marks the location of the ADCP at site $\mathrm{B}$ with the yellow cone indicating the maximal ADCP range. Red circles at sites $A$ and $C$ mark bottom temperature loggers (BTLs). The isotherms show the temperature distribution on 20 May 2017 based on 10 CTD stations (marked on top) observed by R/V Magnus Heinason. The red line shows the $\sigma_{\theta}=27.8 \mathrm{~kg} \mathrm{~m}^{-3}$ isopycnal.

The two BTLs were placed permanently (no recovery option) at sites $\mathrm{A}$ and $\mathrm{C}$ and had battery capacities for many years. The intention was that the results from the field experiment, including the ADCP data, could be used to derive an algorithm giving overflow volume transport from the two bottom temperatures at sites A and C, alone. Since the BTLs may be interrogated from bypassing vessels, this could form the start of a low-cost monitoring system.

The instruments were deployed on 14 August 2016 by R/V Poseidon. On 20 May 2017, R/V Magnus Heinason uploaded the bottom temperature data from the BTLs at sites A and $\mathrm{C}$ and recovered the ADCP and MicroCAT at site B. During both cruises, CTD stations were occupied along a line crossing the valley (Fig. 4).

All temperature measurements from the deployed instruments were checked for data quality and appeared to be of high quality (Hansen et al., 2017a). The conductivity measurements of the MicroCAT showed spikes and a consistent drift through the observational period. They will not be considered here further. The temperature measurements at the three sites were then converted to hourly intervals and daily averaged bottom temperatures determined.

The ADCP data have been quality controlled using a semiautomatic routine, erroneous data flagged and tidal current constituents determined (Hansen et al., 2017a). The tidal currents are quite strong over the IFR (Perkins et al., 1994) and this is also seen in our ADCP measurements. Thus, the major semi-axis of the $M_{2}$ tidal current ellipse for the deepest bin $\left(16.5 \mathrm{~cm} \mathrm{~s}^{-1}\right)$ was more than 3 times the magnitude of the average velocity of that bin $\left(4.9 \mathrm{~cm} \mathrm{~s}^{-1}\right)$ (Table $\mathrm{S} 1$ in the Supplement).

To generate time series of daily averaged velocity, the tidal velocity constituents, determined from the observations (Hansen et al., 2017a), were used to "predict" the tidal veloc- 
ities for all bins during the field experiment. These were subtracted from the original measurements and the resulting time series averaged to daily values for each bin. For the deepest bins, the de-tiding does not alter the daily averages appreciably but, for higher bins with large data gaps, it may prevent biasing in periods with strong tidal currents. The daily averaged velocities were of high quality up to bin 26 , centred at $135 \mathrm{~m}$ depth, $267 \mathrm{~m}$ above the bottom (Table S1).

Both the deep and the upper level velocities were generally directed parallel to the valley axis (Fig. S2). We will use the direction towards $225^{\circ}$ as our $x$ axis and the velocity along this direction is denoted $U$ (Fig. 4). We will focus on the deepest measured velocity at $17 \mathrm{~m}$ above the bottom, which hereafter is denoted "deep velocity", $U_{\mathrm{D}}$, and the uppermost high-quality velocity at $135 \mathrm{~m}$ depth, denoted "top velocity", $U_{\mathrm{T}}$.

\subsection{Hydrographic observations}

In addition to the stations occupied during the deployment and recovery cruises, all CTD profiles within a rectangular area around the $\mathrm{WV}\left(63.5\right.$ to $65^{\circ} \mathrm{N}, 10$ to $\left.14^{\circ} \mathrm{W}\right)$ acquired by the Faroe Marine Research Institute and the University of Hamburg were combined with CTD profiles from the NISE dataset (Nilsen et al., 2008) in the same area (Hansen et al., 2017b). This gave a total of 968 CTD profiles that cover the area fairly well (Fig. S3).

\subsection{Altimetry data}

Altimetry data were downloaded from the global gridded $\left(0.25^{\circ} \times 0.25^{\circ}\right)$ dataset available from Copernicus Marine Environment Monitoring Service (CMEMS) (http://marine. copernicus.eu, last access: 8 August 2018). We use the mean dynamic topography (MDT) for the region covering the IFR (Fig. 3) and we use daily sea level anomalies (SLAs) for two altimetry grid points on either side of the valley (Fig. 4): point $h_{1}\left(64.375^{\circ} \mathrm{N}, 11.875^{\circ} \mathrm{W}\right)$ and point $h_{2}\left(64.625^{\circ} \mathrm{N}\right.$, $\left.12.375^{\circ} \mathrm{W}\right)$. The difference in SLA value between these two points $\Delta h\left(h_{2}-h_{1}\right)$ is a time series with daily values from 1 January 1993 to late June 2017.

\subsection{Statistical methods}

For correlation analyses, we use standard linear (Pearson) correlation coefficients. To assess the statistical significance of the correlation coefficients, we use the modified Chelton method recommended by Pyper and Peterman (1998) to correct for serial correlation in the data. Significance level is indicated by asterisks attached to the correlation coefficient. ${ }^{*}$ indicates $p<0.05,{ }^{* *}$ indicates $p<0.01$ and ${ }^{* * *}$ indicates $p<0.001$. All of these are two-tailed probabilities. The uncertainty of regression coefficients is given as $95 \%$ confidence intervals calculated using the degrees of freedom determined by the modified Chelton method. For the uncertainty of time series averages, we use the standard error mul-

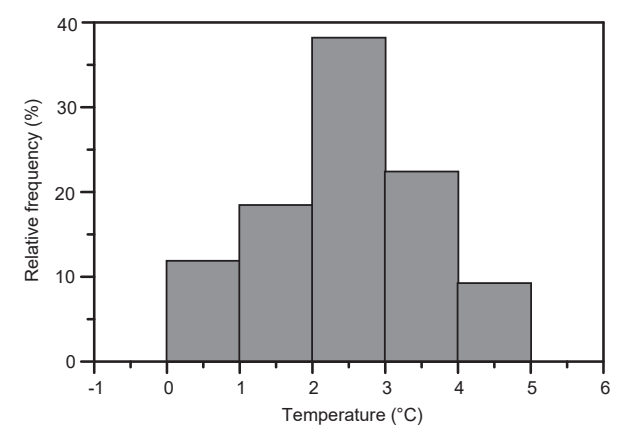

Figure 6. Histogram of the temperature for which $\sigma_{\theta}=$ $27.8 \mathrm{~kg} \mathrm{~m}^{-3}$ for $76 \mathrm{CTD}$ stations in the sill region (station map in Fig. 11a).

tiplied by 1.96 , corrected for serial correlation by replacing the sample size by the "equivalent sample size" (von Storch, 1999) calculated from the autocorrelation of the time series. This ought to be roughly equivalent to a $95 \%$ confidence interval.

\section{Results}

\subsection{In situ observations from the 2016-2017 field experiment}

As shown by the detailed ETOPO1 bathymetry (Fig. 4), the moored instruments were deployed a short distance southwest of the sill of the WV, which is at about $425 \mathrm{~m}$ depth. The region between sites $\mathrm{A}$ and $\mathrm{C}$ spans the deepest parts of the WV (Fig. 5), and any overflow through the WV would be expected to flow through this region with the core close to the ADCP at site B. An example of such a case is provided by the temperature distribution during the recovery cruise in May 2017 when cold water was covering the whole region between sites A and C (Fig. 5).

Typically (e.g. Dickson and Brown, 1994), the $\sigma_{\theta}>$ $27.8 \mathrm{~kg} \mathrm{~m}^{-3}$ criterion is used to define water sufficiently dense to be characterized as overflow. In our field experiment, we do not have sufficient salinity data to provide adequate coverage of density variation and are forced to use temperature instead. From CTD stations in the WV, it is seen that the temperature at which $\sigma_{\theta}=27.8 \mathrm{~kg} \mathrm{~m}^{-3}$ occurs may vary considerably, but in about two-thirds of the cases it is below $3{ }^{\circ} \mathrm{C}$ (Fig. 6). At a later stage (end of Sect. 3), we will also show that our results are not very sensitive to the exact temperature chosen to define overflow water. We will therefore use temperature less than $3{ }^{\circ} \mathrm{C}$ as our criterion and all water that fulfils this criterion will be called "overflow water" even though it may not necessarily cross the IFR into the Atlantic. We can then use the measured bottom temperatures to check the persistence of overflow water at the three sites (Fig. 7). The percentage of hourly observations with bottom 

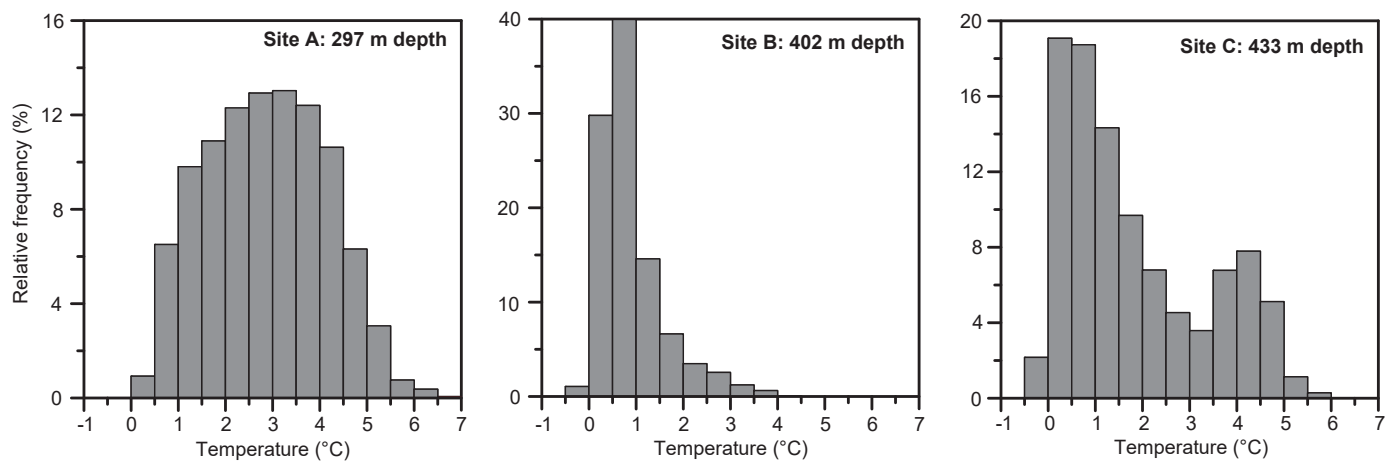

Figure 7. Histograms of bottom temperature at the three deployment sites based on hourly values. Note that the $y$ axes on the three panels have different scales.

Table 2. Correlations between various combinations of weekly averaged observed parameters with statistical significance indicated. These are bottom temperature $\left(T_{\mathrm{A}}, T_{\mathrm{B}}, T_{\mathrm{C}}\right)$ and along-valley components (towards $225^{\circ}$ ) of deep velocity $\left(U_{\mathrm{D}}\right)$ and top velocity $\left(U_{\mathrm{T}}\right) . \Delta U$ is the difference between top and deep velocity $\left(\Delta U=U_{\mathrm{T}}-U_{\mathrm{D}}\right)$. Only statistically significant correlation coefficients $(p<0.05)$ are shown. The others are listed as "n.s.". All parameters have been linearly de-trended before correlation. Introducing lags between the parameters did not give better correlations for any of the cases in the table. ${ }^{*}$ and ${ }^{* * *}$ indicate statistical significance as detailed in Sect. 2.4.

\begin{tabular}{llllll}
\hline & $T_{\mathrm{B}}$ & $T_{\mathrm{C}}$ & $U_{\mathrm{D}}$ & $U_{\mathrm{T}}$ & $\Delta U$ \\
\hline$T_{\mathrm{A}}$ & n.s. & n.s. & n.s. & $0.38^{*}$ & $0.38^{*}$ \\
$T_{\mathrm{B}}$ & & n.s. & $-0.39^{*}$ & n.s. & n.s. \\
$T_{\mathrm{C}}$ & & & $-0.41^{*}$ & $-0.76^{* * *}$ & $-0.66^{* * *}$ \\
$U_{\mathrm{D}}$ & & & & $0.42^{*}$ & n.s. \\
$U_{\mathrm{T}}$ & & & & & $0.92^{* * *}$ \\
\hline
\end{tabular}

temperature below $3{ }^{\circ} \mathrm{C}$ was $53 \%$ for site $\mathrm{A}, 98 \%$ for site $\mathrm{B}$ and $75 \%$ for site $\mathrm{C}$.

Thus, site B was almost always covered by overflow water while site A was in overflow water half the time. Site A has therefore been at the average location of the northwestern boundary of the overflow layer, as was planned. At site C, the bimodal temperature distribution indicates that this site was mostly within the overflow layer, but sometimes the bottom water at this location was replaced by the warmer Atlantic water. The average location of the southeastern overflow boundary has therefore been southeast of site $\mathrm{C}$, but only a short distance to judge from the opposite slopes of isopycnals and bottom (Fig. 5). The distance between sites A and $\mathrm{C}$ is about $12 \mathrm{~km}$, and we therefore conclude that the average width of the overflow layer was less than $20 \mathrm{~km}$ during the field experiment and that its average value may be represented as $(15 \pm 5) \mathrm{km}$.

The bottom temperature variation throughout the field experiment may include a seasonal signal at sites A and B, but apart from that, the variations seem unrelated (Fig. 8a).

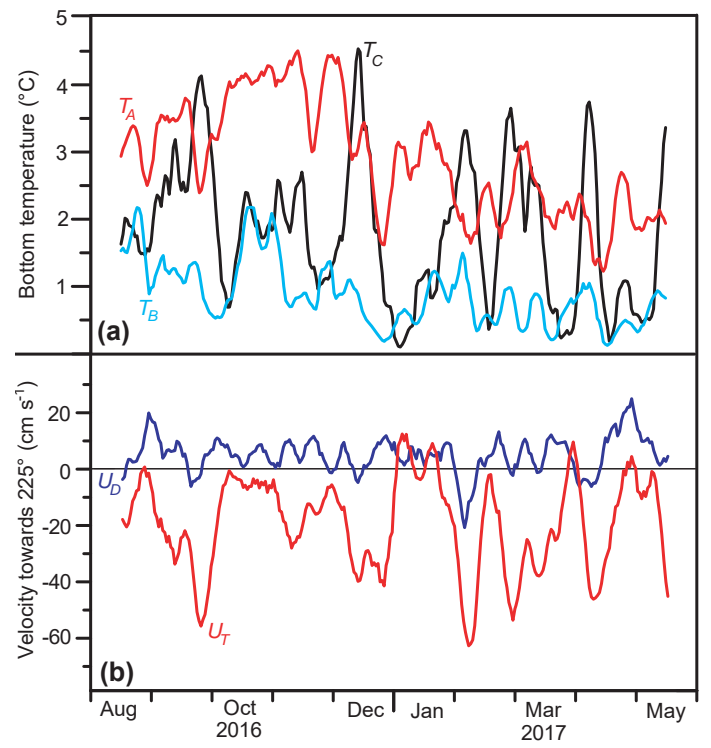

Figure 8. (a) Weekly averaged (7-day running mean) bottom temperatures at the three sites. (b) Weekly averaged velocity towards $225^{\circ}$ at two depths at site B: deep velocity, $U_{\mathrm{D}}$, at $385 \mathrm{~m}$ depth and top velocity, $U_{\mathrm{T}}$, at $135 \mathrm{~m}$ depth.

At site $\mathrm{C}$, the bottom temperature changes rather abruptly between warm and cold conditions consistent with the bimodal bottom temperature distribution in Fig. 7. When detrended to account for possible seasonal or long-term variations, weekly averaged bottom temperatures at the three sites were not significantly correlated with one another (Table 2).

Both top and deep velocities showed considerable variations during the field experiment (Fig. 8b). Averaged over the whole deployment period, the deep velocity was positive (i.e. towards the Atlantic), but it was weak, only $5 \mathrm{~cm} \mathrm{~s}^{-1}$ (Table S1), and the average along-valley velocity decreased with distance from the bottom (Fig. 9a, red line). Only a few profiles showed a "typical overflow shape" with a shallow 

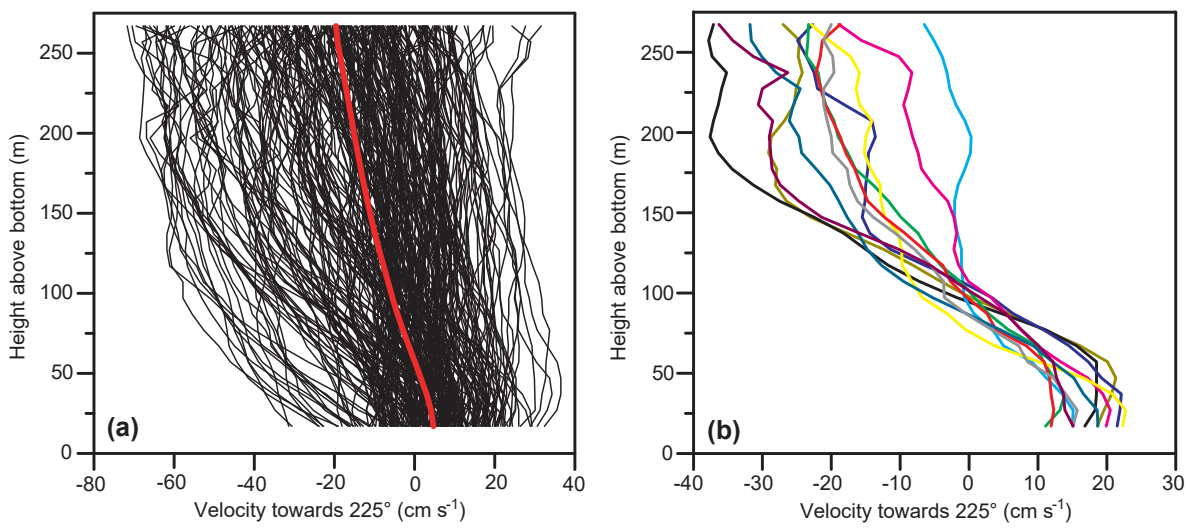

Figure 9. (a) Vertical profiles of $U$ as observed by the ADCP at site B on each day (black lines) and the average profile for the whole deployment period (thick red line). (b) Vertical profiles of $U$ on those days, for which the velocity $47 \mathrm{~m}$ above the bottom (bin 4 ) was $\geq 10 \mathrm{~cm} \mathrm{~s}^{-1}$ while the velocity $107 \mathrm{~m}$ above the bottom (bin 10) was $\leq 0$.

overflow layer and a core some tens of metres above the bottom (Fig. 9b).

For a monitoring system based only on bottom temperature to be successful there has to be a significant relationship between bottom temperature and the velocity close to the bottom. The correlations between bottom temperature and deep velocity (Table 2) are not, however, high. We do find (barely) significant negative correlations between $U_{\mathrm{D}}$ and $T_{\mathrm{B}}$ and between $U_{\mathrm{D}}$ and $T_{\mathrm{C}}$. Thus, a deep flow towards the Atlantic at site B is associated with colder water at these two sites, but the correlation coefficients are low and we find no correlation between $U_{\mathrm{D}}$ and $T_{\mathrm{A}}$. It is therefore not obvious how to monitor WV-overflow by the BTLs at sites A and C, solely.

Remarkably, the bottom temperatures at sites $\mathrm{A}$ and $\mathrm{C}$ are better correlated with the top velocity than with the deep velocity, although with opposite signs (Table 2). They are also significantly correlated with the vertical shear, which may be represented by $\Delta U=U_{\mathrm{T}}-U_{\mathrm{D}}$. This may be explained by the thermal wind equation that links shear and isoline tilt and has the implication that a strong Atlantic inflow $\left(U_{\mathrm{T}} \ll 0\right)$ is associated with increased influence of cold water at site $\mathrm{A}$, but increased influence of warm water at site $\mathrm{C}$. We have to remember, however, that we only have velocity measurements from one site and there may be considerable lateral velocity variations.

Table 2 also shows a weak positive correlation between $U_{\mathrm{D}}$ and $U_{\mathrm{T}}$. This may be due to barotropic forcing from sea level variations or may be caused by frictional drag between the upper and deep flows.

In addition to the long section shown in Fig. 2b, R/V Poseidon made a more detailed CTD survey of the WV during the deployment cruise in August 2016 (Fig. 10). In the northeasternmost section (I), upstream of the sill, the cold and dense water mass extended to fairly shallow levels. Closer to the sill (sections II and III), this water mass was much deeper.
Table 3. Correlation coefficients between weekly averaged in situ parameters and the difference, $\Delta h$, of SLA values between the two selected altimetry grid points (Fig. 4). All parameters have been linearly de-trended before correlation. ${ }^{* * *}$ indicates statistical significance $(p<0.001)$ as detailed in Sect. 2.4.

\begin{tabular}{lcccc}
\hline$U_{\mathrm{T}}$ & $U_{\mathrm{D}}$ & $T_{\mathrm{B}}$ & $T_{\mathrm{A}}$ & $T_{\mathrm{C}}$ \\
\hline $0.86^{* * *}$ & 0.37 & -0.08 & 0.25 & $-0.76^{* * *}$
\end{tabular}

Downstream of the sill (sections IV and V), the cold water had descended further, but cold water was also seen on the southeastern flank of the valley.

\subsection{Altimetry}

From geostrophy, we expect a linear relationship between the tilt of the sea surface from altimetry point $h_{1}$ to point $h_{2}$ (Fig. 4) and the surface velocity perpendicular to the line between the two points with the theoretical coefficient $\alpha_{\text {Theoretical }}=g /(f \cdot s)=2.0 \mathrm{~s}^{-1}$, where $g$ is gravity, $f$ the Coriolis parameter, and $s$ is the distance between the altimetry points. Geostrophic balance is verified by a high correlation coefficient of 0.86 between the SLA difference, $\Delta h$, and the top velocity, $U_{\mathrm{T}}$, even though $U_{\mathrm{T}}$ is measured at $135 \mathrm{~m}$ depth (Table 3).

A linear regression analysis gave $U_{\mathrm{T}}=\alpha_{\mathrm{T}} \cdot \Delta h+\beta_{\mathrm{T}}$ with $\alpha_{\mathrm{T}}=(5.7 \pm 1.1) \mathrm{s}^{-1}$ and $\beta_{\mathrm{T}}=(-14 \pm 3) \mathrm{cm} \mathrm{s}^{-1}$. The value for $\beta_{\mathrm{T}}$ is equivalent to a change in mean dynamic topography of $-7 \mathrm{~cm}(-14 / 2.0)$ from altimetry point $h_{1}$ to point $h_{2}$, which is consistent with Fig. 3. The high value for $\alpha_{\mathrm{T}}$ relative to $\alpha_{\text {Theoretical }}$ was to be expected since the surface current over site $\mathrm{B}$ is probably much stronger than the horizontally averaged current between the two altimetry points (Fig. 4). Using the values of $\alpha_{\mathrm{T}}$ and $\beta_{\mathrm{T}}$ from the regression analysis, we can reproduce $U_{\mathrm{T}}$ for the whole altimetry period (Fig. S4), which indicates that the Atlantic inflow branch 

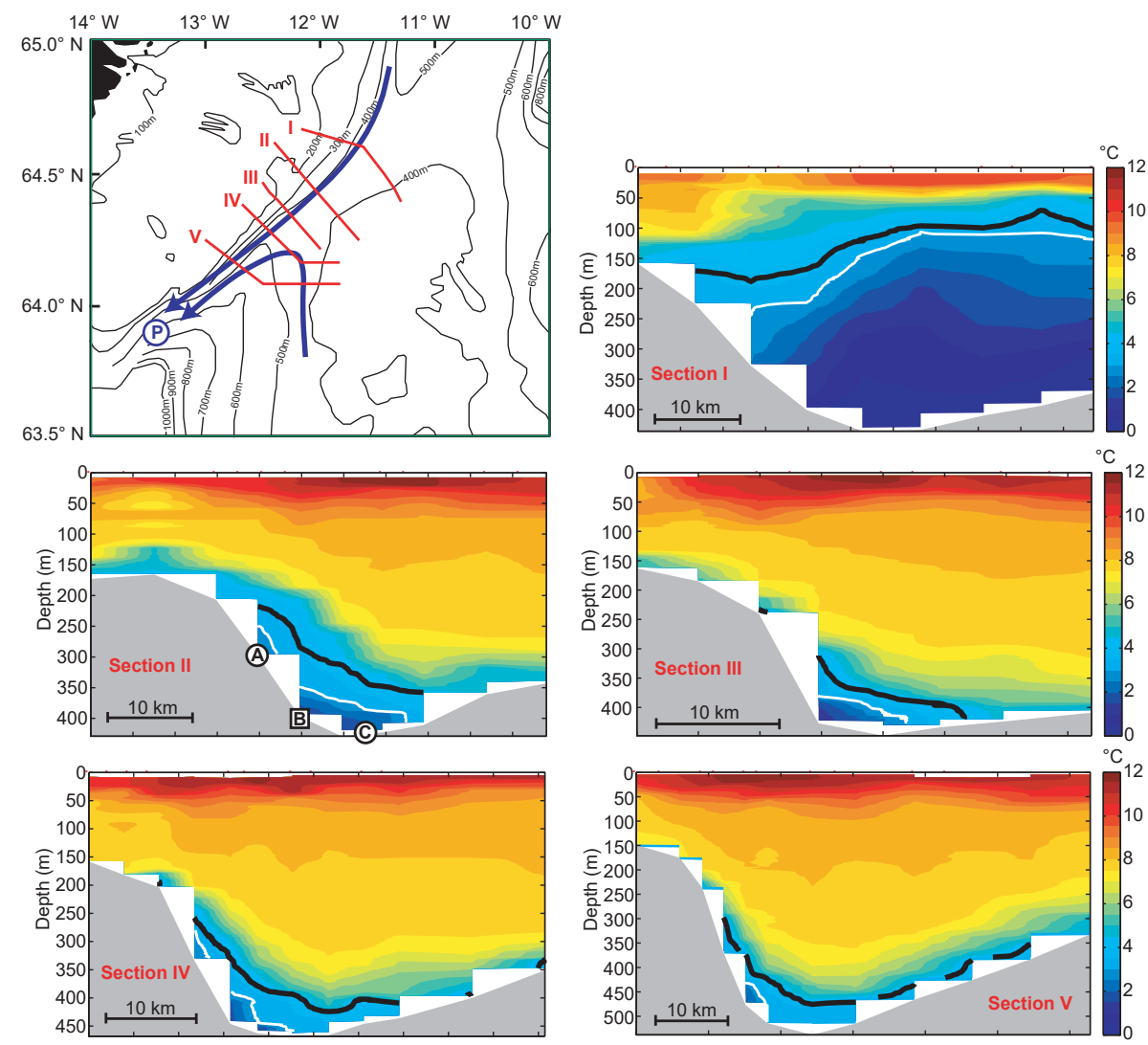

Figure 10. Station map and potential temperature (background colour) along five sections (I to V) crossing the WV, acquired by R/V Poseidon in August 2016. The thick black lines indicate the $\sigma_{\theta}=27.8 \mathrm{~kg} \mathrm{~m}^{-3}$ isopycnal. The white lines indicate the $3^{\circ} \mathrm{C}$ isotherm. Vertical and horizontal scales vary between sections, but the temperature (colour) scales are identical. The moorings of the field experiment were deployed along section II and are shown at the bottom of that section. The blue arrows on the map indicate likely cold-water flow paths, and the blue circle labelled $\mathrm{P}$ on the map marks mooring site $\mathrm{P}$.

over the WV was stronger than average ( $U_{\mathrm{T}}$ more negative) during our field experiment.

The fact that $U_{\mathrm{T}}$ and $U_{\mathrm{D}}$ are significantly correlated (Table 2) indicates that $U_{\mathrm{D}}$ might also be correlated with $\Delta h$. Table 3 lists a positive correlation coefficient between $U_{\mathrm{D}}$ and $\Delta h$, but it is low and not significant. Similarly, we find low and non-significant correlations between $\Delta h$ and the bottom temperatures at sites $\mathrm{A}$ and $\mathrm{B}$, but the bottom temperature at site $\mathrm{C}$ is well correlated with $\Delta h$ as might be expected from the thermal wind equation and Table 2 .

\subsection{Hydrography close to the sill}

From the CTD database, including both recent and historical observations, we have selected stations in the sill region. As shown by the red arrows in Fig. 11a, we defined a coordinate system with origin at site B, $x$ axis towards $225^{\circ}$ (Fig. 4) and $y$ axis towards $135^{\circ}$. We then selected CTD stations with $|y| \leq 50 \mathrm{~km}$ and $|x| \leq 25 \mathrm{~km}$ and plotted various parameters against the $y$ coordinate (Fig. 11b-d) although there is also considerable variation along the valley ( $x$ axis) as demonstrated by the detailed CTD survey in Fig. 10.

The variation of bottom depth from the CTD stations along the $y$ axis (Fig. 11b) is consistent with a sill depth around $425 \mathrm{~m}$, as indicated in Fig. 4. At most locations along this section, bottom temperature varies considerably, indicating shifts between overflow and Atlantic water presence (Fig. 11c). Close to site B, however, the bottom water was consistently cold. In the interval from $y=-10 \mathrm{~km}$ to $y=6 \mathrm{~km}$ (grey areas in Fig. 11b-d), there were altogether 39 stations with average bottom temperature $0.5^{\circ} \mathrm{C}$ and none of them exceeded $3{ }^{\circ} \mathrm{C}$. This is consistent with the observations from the field experiment that had very few hourly averaged bottom temperatures above $3^{\circ} \mathrm{C}$ at site $\mathrm{B}$ (Fig. 7).

Using the $27.8 \mathrm{~kg} \mathrm{~m}^{-3}$ isopycnal to denote the upper boundary of the overflow layer, a similar picture is seen (Fig. 11d). Along most of the section, there were CTD stations with the whole water column less dense than this value (isopycnal height of 0 in Fig. 11d), but not in the vicinity of site $\mathrm{B}$. 

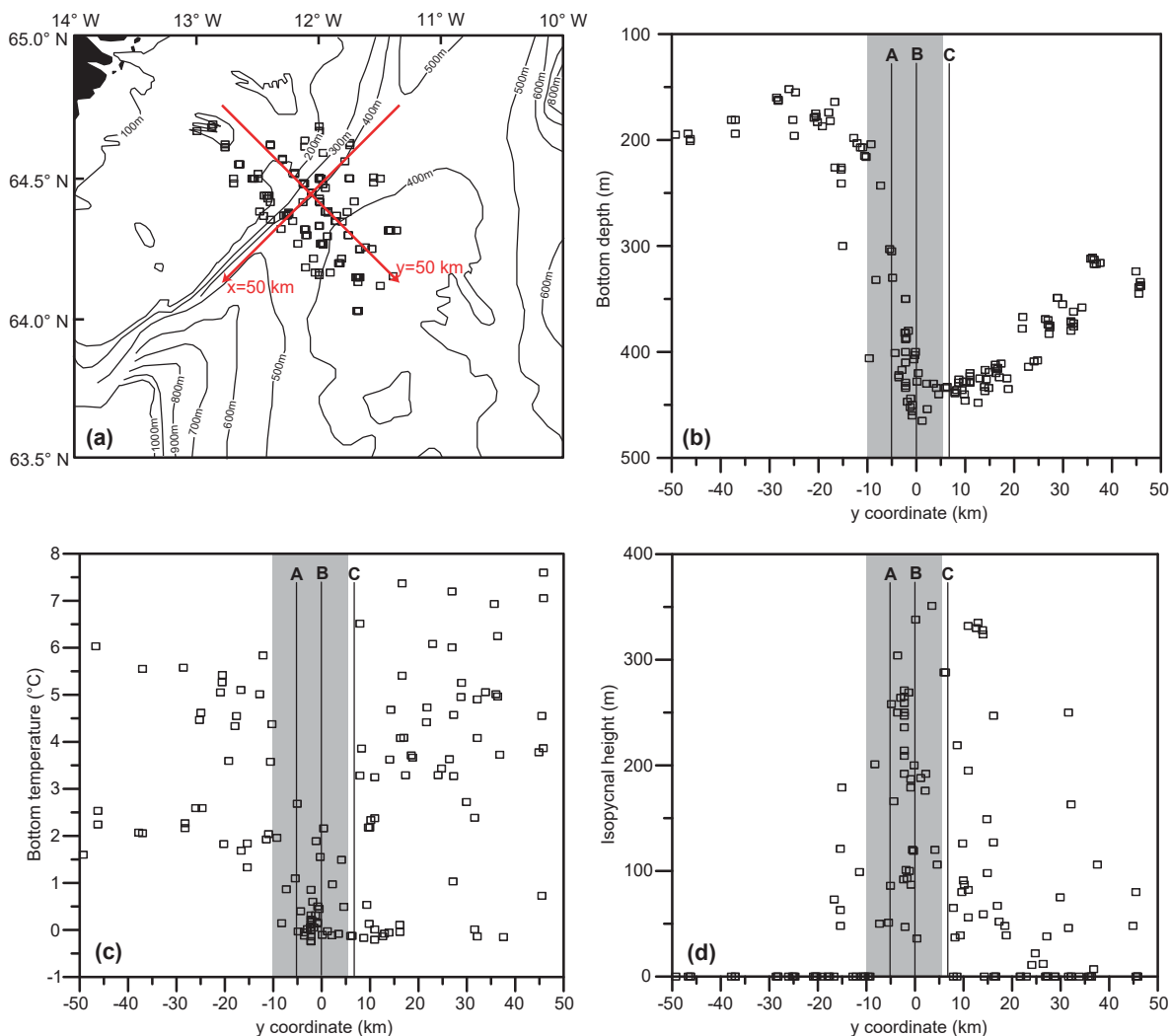

Figure 11. (a) Selected CTD stations in the sill region with coordinate system indicated by red arrows. (b) Variation along the $y$ axis of bottom depth. (c) Variation along the $y$ axis of bottom temperature for profiles with the CTD reaching less than $40 \mathrm{~m}$ from the bottom. (d) Variation along the $y$ axis of the height of the $\sigma_{\theta}=27.8 \mathrm{~kg} \mathrm{~m}^{-3}$ isopycnal above the bottom. Isopycnal height of 0 indicates that the whole water column was less dense than $27.8 \mathrm{~kg} \mathrm{~m}^{-3}$. (b-d) The three mooring sites of the field experiment are marked by thin vertical lines. The origin of the $y$ axis is located at site $\mathrm{B}$, and the grey areas highlight the region from $y=-10 \mathrm{~km}$ to $y=6 \mathrm{~km}$.

From Table 3, one might perhaps expect that some of the variability in Fig. 11 could be derived from altimetry, but attempts to identify any such relationship did not give statistically significant results, whether considering bottom temperature or isopycnal depth/height.

\subsection{Transport per unit length at site B}

To get a first impression of the volume transport of overflow through the Western Valley, we integrate the average velocity profile towards $225^{\circ}$ at site B (red curve in Fig. 9a) from the bottom up to the level where it is zero (about $60 \mathrm{~m}$ above the bottom). This gives a value of $1.5 \mathrm{~m}^{2} \mathrm{~s}^{-1}$, which is in the form of a volume transport per unit length across the valley (also termed transport density).

This value should include both overflow water and any warmer water flowing towards the Atlantic and it might be considered to be an upper limit for the average transport per unit length of overflow water at site B during the field experiment. Transport per unit length might not, however, depend linearly on velocity, so this is not necessarily the appropriate average. In order to estimate a more reliable average and de- termine the temporal variability, we have generated a time series that is intended to represent daily averaged transport per unit length of overflow water at site $\mathrm{B}$, which is labelled $q_{0}$.

To do that requires daily estimates of the height of the overflow layer, which can be used as the upper integration limit of the velocity profile. As illustrated in Fig. 12, we use the $3{ }^{\circ} \mathrm{C}$ isotherm as the upper boundary and calculate its height above bottom at site $\mathrm{B}, z$, for each day in two steps. The first step involves finding the height, $\Delta z_{1}$, of the $3^{\circ} \mathrm{C}$ isotherm above (or below) bottom at site $\mathrm{A}$ by using the bottom temperature, $T_{\mathrm{A}}$, at this site. The second step involves calculating the deepening (or rising), $\Delta z_{2}$, of this isotherm from site A to site B by using the tilt of the isotherm, $\varphi$, which is assumed to be equal to the tilt of the $27.8 \mathrm{~kg} \mathrm{~m}^{-3}$ isopycnal and may be derived by using the thermal wind equation:

$$
\begin{aligned}
\tan (\varphi) & =\frac{\partial \rho / \partial y}{\partial \rho / \partial z}=\frac{\rho \cdot f \cdot(\partial U / \partial z)}{g \cdot(\partial \rho / \partial z)} \cong \frac{\rho \cdot f}{g} \\
& \cdot\left\langle(\partial \rho / \partial z)^{-1}\right\rangle \cdot \frac{\Delta U}{\Delta Z},
\end{aligned}
$$

where $\rho$ is density, $f$ the Coriolis parameter, $g$ the acceleration of gravity, and instantaneous values of the inverse den- 


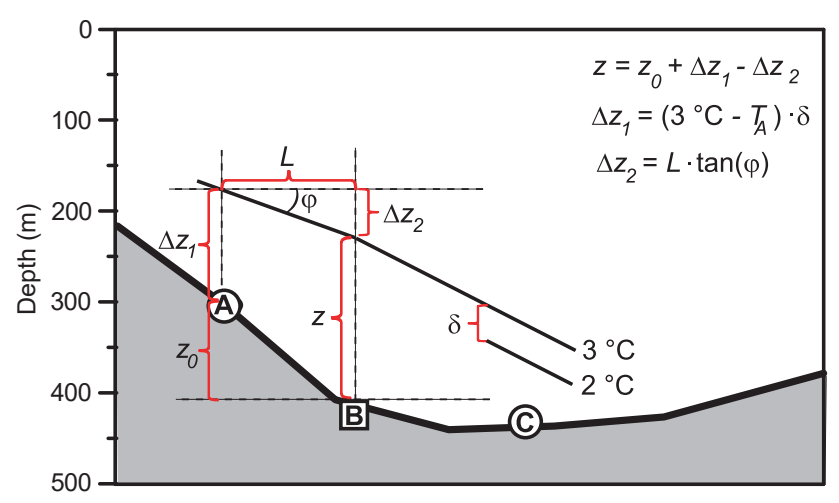

Figure 12. Sketch illustrating the determination of the height of the overflow layer at site $\mathrm{B}, z$. If daily averaged bottom temperature at site $\mathrm{B}$ was $>3{ }^{\circ} \mathrm{C}, z$ was set to zero. Otherwise, $z$ was required not to be less than a minimum value of $25 \mathrm{~m}$.

sity gradient $(\partial \rho / \partial z)^{-1}$ have been replaced by their average value $\left\langle(\partial \rho / \partial z)^{-1}\right\rangle . \Delta U / \Delta Z$ is the vertical shear of the current determined from the ADCP profile over a vertical distance, $\Delta Z$, which was chosen to cover the depth interval over which the isotherm deepens or rises from site A to site B.

An approximate value for $\left\langle(\partial \rho / \partial z)^{-1}\right\rangle$ was estimated from the CTD stations deeper than $300 \mathrm{~m}$ in Fig. 11a by averaging the vertical distance between the 27.75 and the $27.85 \mathrm{~kg} \mathrm{~m}^{-3}$ isopycnals. These CTD data were also used to verify that the vertical distance between neighbouring isotherms for most cases is fairly constant (Fig. S5) and to find its average value, $\delta=31 \mathrm{~m}$ (Fig. 12). Both of these estimates as well as Eq. (1) are associated with considerable uncertainty, and the estimated values for $z$ will only be approximate but their validity may be evaluated independently by using the bottom temperature at site $\mathrm{C}$.

This is done by extending the $3{ }^{\circ} \mathrm{C}$ isotherm further from site $\mathrm{B}$ to site $\mathrm{C}$ by a similar method, where $\Delta U / \Delta Z$ is calculated from the bottom up to the estimated isotherm height at site B. The correlation coefficient between the calculated isotherm height and bottom temperature at site $\mathrm{C}$ was $-0.73^{* * *}$ for weekly averages. This adds confidence to the procedure for calculating $z$, and we have therefore used the estimated values for $z$ (Fig. S6) to generate a time series for $q_{0}$ by integrating the ADCP profile from the bottom up to $z$.

Averaged over the duration of the field experiment, the overflow transport per unit length, $q_{0}$, was $(1.4 \pm 2.8) \mathrm{m}^{2} \mathrm{~s}^{-1}$, where the uncertainty was determined as the standard error corrected for serial correlation multiplied by 1.96 (Sect. 2.4). The variations of $q_{0}$ were related to the variations of the top velocity, $U_{\mathrm{T}}$, with a highly significant correlation coefficient $\left(R=0.51^{* * *}\right)$ for daily averages, which increased to $R=0.64^{* * *}$ for weekly averages (Fig. 13a).
Table 4. Results from a sensitivity analysis, listing estimated average values for the overflow transport per unit length at site B, $q_{0}$, in units of $\mathrm{m}^{2} \mathrm{~s}^{-1}$ during the field experiment and during the altimetry period for different choices of the isotherm defined as the top of the overflow layer. Values for the altimetry period are calculated from regression coefficients determined similarly as for Fig. 13b. Uncertainties are $95 \%$ confidence intervals calculated from standard errors after correction for serial correlation (Sect. 2.4).

\begin{tabular}{lccccr}
\hline Isotherm: & $2{ }^{\circ} \mathrm{C}$ & $3{ }^{\circ} \mathrm{C}$ & $4{ }^{\circ} \mathrm{C}$ & $5{ }^{\circ} \mathrm{C}$ & $6{ }^{\circ} \mathrm{C}$ \\
\hline Field exp.: & $1.3 \pm 1.8$ & $1.4 \pm 2.8$ & $1.5 \pm 3.7$ & $0.7 \pm 5.0$ & $-1.5 \pm 6.5$ \\
Alt. per.: & $2.0 \pm 0.3$ & $2.8 \pm 0.5$ & $3.5 \pm 0.7$ & $3.4 \pm 1.0$ & $2.2 \pm 1.3$ \\
\hline
\end{tabular}

Since the weekly averaged values for $U_{\mathrm{T}}$ were highly correlated with the SLA difference $\Delta h$ (Table 3), this link between $q_{0}$ and $U_{\mathrm{T}}$ indicates that there may also be a link between $q_{0}$ and $\Delta h$. That is indeed the case since the correlation coefficient between $q_{0}$ and $\Delta h$ was $R=0.60^{* *}$ for weekly averages (Fig. 13b).

Although the correlation coefficient in Fig. 13b is significant, the relationship is not necessarily linear. Nevertheless, the scatter seems too high to warrant high-order fits. We have therefore used the regression coefficients of Fig. 13b to reproduce values for $q_{0}$ for the whole altimetry period (Fig. 14). The seasonal variation of $q_{0}$ does not seem to be very pronounced but there is an indication of strengthened overflow during summer (Fig. 14b). The long-term variation shows that our field experiment is likely to have taken place during a period of weak WV-overflow (Fig. 14a). From the beginning of 1993 to the end of 2016, the regression equation gives an average value of $2.7 \mathrm{~m}^{2} \mathrm{~s}^{-1}$ for $q_{0}$. This long-term estimate is almost twice as high as during the field experiment.

In Fig. 14a, we have indicated the uncertainty (95\% confidence) interval of $q_{0}$ during the altimetry period based on the confidence intervals of the two regression coefficients (Fig. 13b). There are, however, two additional sources of uncertainty, which are not included in this. One of these is the uncertainty of the height, $z$, of the $3^{\circ} \mathrm{C}$ isotherm at site $\mathrm{B}$ (Fig. 12). The second additional uncertainty source derives from our choice of using the $3{ }^{\circ} \mathrm{C}$ isotherm to define overflow water. Although this choice according to Fig. 6 should ensure that most of the water defined in this way is denser than $27.8 \mathrm{~kg} \mathrm{~m}^{-3}$, there are clearly exceptions as demonstrated in Fig. 10. On that occasion, the $27.8 \mathrm{~kg} \mathrm{~m}^{-3}$ isopycnal (black lines) was located above the $3{ }^{\circ} \mathrm{C}$ isotherm (white lines) on all the sections.

Both of these uncertainty sources involve the height of the overflow layer at site $\mathrm{B}$, which is used to determine $q_{0}$ for each day. The effect of both can therefore be estimated by running a sensitivity analysis where we add (or subtract) certain amounts to (or from) $z$ before calculating $q_{0}$. This is equivalent to using temperatures other than $3^{\circ} \mathrm{C}$ to define the top of the overflow layer, and the calculations are easily car- 

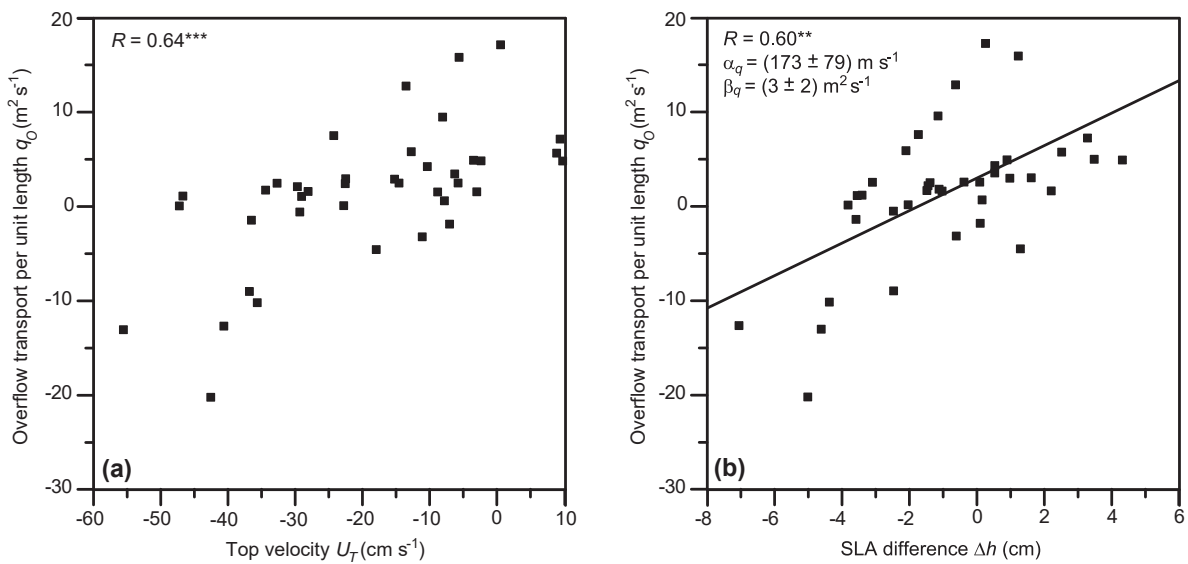

Figure 13. (a) Weekly averaged overflow transport per unit length at site B, $q_{0}$, plotted against weekly averaged top velocity $U_{\mathrm{T}}$. (b) Weekly averaged overflow transport per unit length at site B plotted against weekly averaged difference in SLA values $\Delta h$. The correlation coefficients $(R)$ are shown with statistical significance indicated, and in panel (b) also the regression coefficients with uncertainties given by the $95 \%$ confidence intervals (Sect. 2.4) and the regression line $q_{0}=\alpha_{q} \cdot \Delta h+\beta_{q}$ are shown.
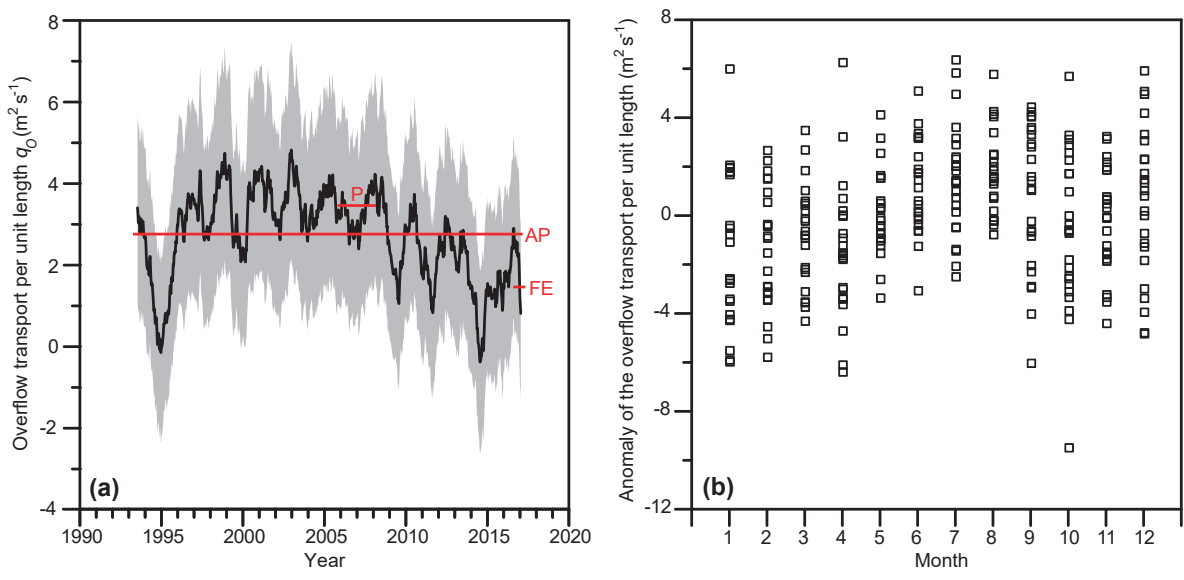

Figure 14. (a) Low-passed (365-day running mean) overflow transport per unit length at site B, $q_{0}$ (black curve), with uncertainty interval (grey area) from 1993 to 2016 based on satellite altimetry and the regression equation in Fig. 13b. Red lines indicate the estimated overflow transport per unit length averaged over the field experiment (FE), the whole altimetry period (AP) and the duration of the ADCP measurements at site $\mathrm{P}(\mathrm{P})$. (b) Monthly averages of the anomaly of the overflow transport per unit length, defined as the deviation from the 365-day running mean centred on the month.

ried out by modifying the formulas for calculating $z$ (Fig. 12) accordingly. The results of the sensitivity analysis are presented in Table 4 . Going from 3 to $4{ }^{\circ} \mathrm{C}$ (by adding $\delta=31 \mathrm{~m}$ to $z$ for each day) increased the value of $q_{0}$ only slightly for the field experiment, but some more for the whole altimetry period. Going to higher isotherms actually reduced the estimates of $q_{0}$.

The reason for this reduction is to be found in the typical vertical variation of velocity (Fig. 9a). The value for $q_{0}$ is determined by integrating the velocity over the overflow layer. When the height of this layer is increased, the integral reaches levels where the velocity is progressively more often negative, making the integral decrease. This explains why the value for $q_{0}$ is not very sensitive to the uncertainties in deriving $z$ or to our criterion for defining overflow water.

\section{Discussion}

\subsection{Average volume transport of WV-overflow}

The results of our field experiment present us with a conundrum: on the one hand, water with overflow character is present at site B almost all the time and also shows little variability in historical hydrographic data. Since the site is close to the sill, this water would be expected to flow more or less continuously towards the Atlantic. Instead, the daily averaged deep velocity is away from the Atlantic $30 \%$ of the 
time and even when it is towards the Atlantic, it is weak and variable (Fig. 8b). Only a few days showed typical overflow velocity profiles during the field experiment (Fig. 9b).

In addition to this, there are the arguments for a strong and persistent WV-overflow based on theory and observations that were mentioned in the introduction. We therefore need to ask whether the instruments deployed in the field experiment were located so that they missed the overflow plume. That is not likely. The bottom temperature distributions (Fig. 7) combined with bottom topography (Fig. 5) indicate that site $\mathrm{A}$ and site $\mathrm{C}$ are close to the upper and deeper average boundaries of the overflow layer, respectively. Bottom temperatures from the field experiment (Fig. 8a) and from the historical CTD dataset (Fig. 11c) likewise confirm that the coldest bottom water is usually found close to site B as are the largest isopycnal heights (Fig. 11d).

Thus, the average velocity of the overflow core is not likely to be much stronger than the ADCP measurements at site B (Fig. 9) while the bottom topography (Fig. 5) combined with the expected interface slope indicate that the height of the overflow layer also is close to its maximum at site B. The average transport per unit length measured at site $\mathrm{B},(1.4 \pm 2.8) \mathrm{m}^{2} \mathrm{~s}^{-1}$, is therefore likely an overestimate for the overflow layer as a whole. In Sect. 3.1, we argued that the average width of the overflow layer during the field experiment was $(15 \pm 5) \mathrm{km}$. We therefore conclude that the average transport of overflow water (colder than $3{ }^{\circ} \mathrm{C}$ ) through the WV during the field experiment did not exceed $\left(1.4 \mathrm{~m}^{2} \mathrm{~s}^{-1}\right) \times(15 \mathrm{~km}) \approx 0.02 \mathrm{~Sv}$ with an uncertainty on the order of $0.05 \mathrm{~Sv}$.

These arguments are supported by the conclusions from the inviscid two-layer hydraulic model in the Supplement, which indicates that a strong WV-overflow should have been seen by the ADCP at site $\mathrm{B}$. The model also verifies that the overflow transport per unit length at site B multiplied by a fixed width of $20 \mathrm{~km}$ generally will give an overestimate of the volume transport.

The overflow transport per unit length, $q_{0}$, has both positive and negative values, which reduces the average to a small value. One might be tempted to argue that only the positive values should be used, but that would only be appropriate if we can assume that most of the water flowing towards the Atlantic during positive transport events would continue in that direction and that the return flow (towards the Norwegian Sea) outside of the events would carry a different water mass - not overflow water. The negative correlation coefficient between $T_{\mathrm{B}}$ and $U_{\mathrm{D}}$ in Table 2 does indicate that the returning water ( $U_{\mathrm{D}}$ negative) tends to be warmer than during overflow events ( $U_{\mathrm{D}}$ positive), but the difference is not very pronounced and the returning water was always sufficiently cold to be classified as overflow (Figs. 7 and S7).

Thus, it seems difficult to argue that the average overflow transport during the field experiment was higher than $(0.02 \pm 0.05) \mathrm{Sv}$. From Fig. 14a it appears, however, that $q_{0}$, and hence also WV-overflow was relatively weak dur- ing our field experiment and that the average of $q_{0}$ over the whole altimetry period was twice as high. Uncertainties in the regression coefficients (Fig. 13b) imply an uncertainty in $q_{0}$ of about $2 \mathrm{~m}^{2} \mathrm{~s}^{-1}$. In addition to this, there is the uncertainty in our estimate of the height of the $3{ }^{\circ} \mathrm{C}$ isotherm, $z$, and using a different criterion for defining overflow water will also affect $q_{0}$. Both of these were estimated in Table 4, which indicates that they at most can increase the long-term estimate of $q_{0}$ by less than $1 \mathrm{~m}^{2} \mathrm{~s}^{-1}$.

A maximum estimate of the long-term average $q_{0}$ is therefore around $5 \mathrm{~m}^{2} \mathrm{~s}^{-1}$, which implies a maximum long-term average WV-overflow transport of $\left(5 \mathrm{~m}^{2} \mathrm{~s}^{-1}\right) \times(20 \mathrm{~km})=0.1 \mathrm{~Sv}$. This value represents the maximum average transport of overflow water, i.e. water colder than $3{ }^{\circ} \mathrm{C}$, but even including water up to $6{ }^{\circ} \mathrm{C}$ in temperature would not increase this value according to Table 4.

\subsection{Why is WV-overflow so weak?}

From our field experiment, we thus find an overflow volume transport that is much less than what one might expect from the arguments presented in the introduction. The problem is conveniently illustrated by two of the sections in Fig. 10. In section I, the $27.8 \mathrm{~kg} \mathrm{~m}^{-3}$ isopycnal reaches almost to the surface, but in the neighbouring section II, it is close to the bottom. Why does the cold and dense water in section I not penetrate to section II and further through the WV?

The answer seems to be associated with the Atlantic inflow to the Norwegian Sea in the upper layers over the WV. From Fig. 13a, a strong Atlantic inflow is associated with a weak or negative overflow transport per unit length and there are several possible explanations for this:

- Frictional drag between the Atlantic inflow and overflow will tend to reduce overflow velocity.

- The vertical shear between the Atlantic inflow and the overflow will make the interface between the two water masses tilt more strongly, making the overflow layer both thinner and narrower as the strong correlation between $T_{\mathrm{C}}$ and $\Delta U$ in Table 2 verifies.

- The flow path of the Atlantic inflow is associated with a sea level drop, $\Delta \eta$, from the $\mathrm{WV}$ to the region east of Iceland (Fig. 3) as illustrated in the idealized sketch in Fig. 15. The barotropic forcing induced by this $\left(g \cdot \rho_{0}\right.$. $\Delta \eta$ ) will counteract the baroclinic forcing that drives the overflow $(g \cdot \Delta \rho \cdot \Delta D)$. With a density difference $\Delta \rho=0.5 \mathrm{~kg} \mathrm{~m}^{-3}$, a sea level difference, $\Delta \eta$, of $10 \mathrm{~cm}$ can neutralize a difference in interface depth, $\Delta D$, of $200 \mathrm{~m}$ (Fig. 15).

The last two points above are elaborated in the inviscid twolayer model (Fig. S8), which confirms that with realistic choices of parameters, these effects can lead to a very weak WV-overflow. The model also demonstrates the effect of the 

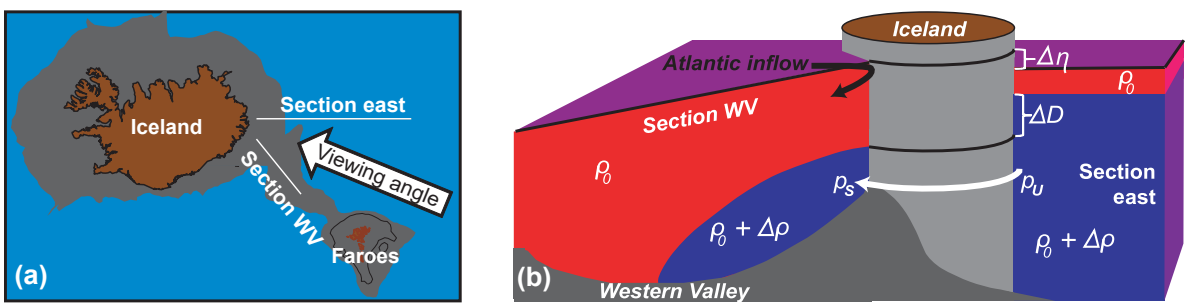

Figure 15. (a) The Iceland-Faroe region with two sections indicated by white lines: one going eastwards (section east) and one crossing the WV (section WV). (b) An idealized sketch of the two sections as seen from the Norwegian Sea towards Iceland (viewing angle in panel a). The ocean is approximated as a two-layer system with density difference $\Delta \rho$. The Atlantic inflow turns southwards after passing through the WV, which is associated with a sea level difference $\Delta \eta$ between the two sections (Fig. 3). The thick white arrow illustrates a water parcel of dense water flowing along the Icelandic slope from east of Iceland through the WV without changing depth. Ignoring friction, the Bernoulli equation gives the acceleration of the water parcel in terms of the pressure change along the path, which may be expressed as $\Delta p=p_{\mathrm{U}}-p_{\mathrm{S}}=g \cdot\left(\Delta \rho \cdot \Delta D-\rho_{0} \cdot \Delta \eta\right)$.

bottom topography. A weakly sloping bottom will lead to a thin overflow layer and weak transport.

Even without friction, the effects of the Atlantic inflow are thus sufficient to reduce WV-overflow to the level that we have observed, and friction will reduce the overflow even more. How important frictional drag is compared to the inviscid mechanisms listed above is difficult to assess but taken together, all these mechanisms are clearly able to allow the Atlantic inflow to suppress WV-overflow to the level observed.

\subsection{Implications}

If WV-overflow is as weak as our observations indicate, how can we explain the persistent bottom current with average core speed of $50 \mathrm{~cm} \mathrm{~s}^{-1}$ at site $\mathrm{P}$ some $90 \mathrm{~km}$ downstream from the WV sill (Fig. 2)? As argued by Perkins et al. (1998) and Beaird et al. (2013), the original source of this current must be overflow across the IFR. The width of the current and hence its volume transport are, however, not well constrained by observations and neither is the transport increase due to entrainment downstream of the ridge. Nevertheless, it has been argued by Perkins et al. (1998) that the original overflow feeding this current must have been at least $0.7 \mathrm{~Sv}$, whereas Voet (2010) suggested an average of $0.5 \pm 0.3 \mathrm{~Sv}$.

A reliable estimate of the volume transport of the bottom current at site $\mathrm{P}$ and its source will probably require additional observational effort. Nevertheless, it seems doubtful that WV-overflow can be its only source even though Fig. 14a indicates that $\mathrm{WV}$-overflow was considerably stronger during the ADCP measurements at site P (Voet, 2010) than during our field experiment. That still leaves other parts of the IFR, however, and Beaird et al. (2013) argued that overflow from the whole northwestern half of the IFR could feed into this current. As exemplified in Fig. 2b, cold water is certainly observed to cross the crest of the ridge south of the WV and is frequently seen close to the bottom in historical CTD profiles (Fig. S3).

In their map summarizing the currents southeast of Iceland (their plate 1), Perkins et al. (1998) show a bottom flow cir- culating into and out of the Atlantic end of the WV. Such a current (curved blue arrow on the map in Fig. 10) would explain the cold water over the southeastern slope of the valley in sections IV and V of Fig. 10 and would be a pathway for overflow water from more southerly parts of the ridge to flow towards site $\mathrm{P}$.

This current may be fed by two different mechanisms generating overflow water across the IFR. One is the mechanism illustrated in Fig. 15, by which cold, dense water of Arctic origin pushes its way across the ridge analogous to the overflows through the Denmark Strait and Faroe Bank Channel. This mechanism is likely strongest in summer (Voet, 2010; Olsen et al., 2016) and is the mechanism represented in hydraulic two-layer models (e.g. Wilkenskjeld and Quadfasel, 2005; Voet, 2010; Olsen et al., 2016) like the one presented in the Supplement (Fig. S8).

The other mechanism is subduction along the IcelandFaroe Front (Read and Pollard, 1992; Perkins et al., 1998), which is strongly winter intensified (Beaird et al., 2016). The resulting water mass has a low salinity and most of it is not sufficiently dense to fulfil our criterion for overflow water. Part of it joins the Atlantic inflow to the Norwegian Sea (Beaird et al., 2016), but any fraction that flows into the Atlantic is likely to join the bottom current at site P. Our rejection of the Western Valley as an important overflow contribution is therefore not incompatible with the observations at this site.

When considering their contribution to the North Atlantic Deep Water and AMOC, the overflow waters generated by these two mechanisms play similar roles although modified by density differences. For budget estimates of the Arctic Mediterranean, in contrast, they behave quite differently since the frontal subduction of Atlantic water occurs before the Atlantic water reaches the section where volume transport of Atlantic inflow between Iceland and the Faroe Islands is monitored (Hansen et al., 2015). Overflow water generated by frontal subduction therefore should not be included in these budgets. 


\section{Conclusions and perspectives}

From the measurements of our field experiment, we estimate the average WV-overflow during the experiment to have been $(0.02 \pm 0.05) \mathrm{Sv}$. Our experiment was probably during a period of relatively weak WV-overflow but combining these measurements with historical CTD observations and satellite altimetry, we conclude that the volume transport of overflow through the WV has been at most $0.1 \mathrm{~Sv}$ on average over the last two decades.

The main reason for this low value seems to be the Atlantic water flowing into the Norwegian Sea in the upper layers, which may suppress the overflow in at least three different ways. Firstly, friction between the oppositely moving Atlantic inflow and overflow may slow down the overflow. Secondly, the shear between the overflow water and the Atlantic water is associated with increased tilt of the interface between the two water masses so that the overflow layer becomes thinner and narrower and its volume transport weaker. Thirdly, the Atlantic inflow is associated with a sea level difference between the WV sill region and the upstream basin feeding the overflow. The barotropic pressure gradient induced by this sea level difference counteracts the baroclinic pressure gradient at depth, which otherwise would push the overflow water through the WV.

All of these tend to reduce the overflow and make the interface deeper. The effect of a deeper interface is further enhanced by a weakly sloping bottom on the Icelandic flank of the WV, which also reduces the height of the overflow layer and allows bottom friction to prevent high overflow velocities.

With our determination of a weak WV-overflow, one piece of the IFR-overflow puzzle has been found, but the whole picture still seems rather hazy. A future, more reliable estimate of the volume transport of the bottom current at site $\mathrm{P}$ (Fig. 2a) might help considerably. For the present, we can only conclude that the total IFR-overflow is likely to be considerably less than the canonical $1 \mathrm{~Sv}$ value.

One of the motivations for the field experiment was to design a monitoring system for WV-overflow based on the bottom temperature loggers at site $\mathrm{A}$ and site $\mathrm{C}$. The results from the field experiment did not support the basic hypothesis on which this system was based and indicate that monitoring might be better achieved through the use of altimetry data. At the same time, the low transport value makes the motivation for monitoring WV-overflow rather doubtful.

Data availability. The ADCP data from the field experiment are freely available as three files: ftp://www. envofar.fo/Currents/ADCP_Data/IFWV1608_Ensemble.txt, ftp://www.envofar.fo/Currents/ADCP_Data/IFWV1608_Speed.txt, and ftp://www.envofar.fo/Currents/ADCP_Data/IFWV1608_ Direction.txt (ENVOFAR, 2018), while the CTD data acquired by the University of Hamburg during the deployment cruise are avail- able at https://doi.org/10.1594/PANGAEA.890699 (Quadfasel, 2018).

Supplement. The supplement related to this article is available online at: https://doi.org/10.5194/os-14-871-2018-supplement.

Competing interests. The authors declare that they have no conflict of interest.

Acknowledgements. The 2016-2017 field experiment as well as part of the analysis was funded by the Danish Energy Agency as part of the Arctic Climate Support Programme (Western Valley Overflow project). CTD data were obtained through the co-operative project "RACE II - Regional Atlantic Circulation and Global Change" funded by the German Federal Ministry for Education and Research (BMBF), Förderkennzeichen 03F0729B. This study was supported by the AtlantOS and the Blue-Action projects, both of which have received funding from the European Union's Horizon 2020 research and innovation program under grant agreement nos. 633211 and 727852, respectively. We thank John Whitehead and two anonymous referees for encouraging and constructive comments.

Edited by: Mario Hoppema

Reviewed by: John Whitehead and two anonymous referees

\section{References}

Beaird, N. L., Rhines, P. B., and Eriksen, C. C.: Overflow waters at the Iceland-Faroe Ridge observed in multiyear Seaglider surveys, J. Phys. Oceanogr., 43, 2334-2351, https://doi.org/10.1175/JPOD-13-029.1, 2013.

Beaird, N. L., Rhines, P. B., and Eriksen, C. C.: Observations of seasonal subduction at the Iceland-Faroe Front, J. Geophys. Res.-Oceans, 121, 4026-4040, https://doi.org/10.1002/2015JC011501, 2016.

Dickson, R. R. and Brown, J.: The production of North Atlantic deep water, sources, rates, and pathways, J. Geophys. Res., 99, 12319-12341, https://doi.org/10.1029/94JC00530, 1994.

ENVOFAR: ADCP data from the field experiment, Environmental data on terrestrial and marine ecosystems in the Faroe Islands, available at: ftp://www.envofar.fo/Currents/ADCP_Data/, last access: 15 August 2018.

Hansen, B. and Østerhus, S.: North Atlantic-Nordic Seas exchanges, Prog. Oceanogr., 45, 109-208, 2000.

Hansen, B., Østerhus, S., Quadfasel, D., and Turrell, W.: Already the day after tomorrow?, Science, 305, 953-954, 2004.

Hansen, B., Larsen, K. M. H., Hátún, H., Kristiansen, R., Mortensen, E., and Østerhus, S.: Transport of volume, heat, and salt towards the Arctic in the Faroe Current 1993-2013, Ocean Sci., 11, 743-757, https://doi.org/10.5194/os-11-7432015, 2015.

Hansen, B., Larsen, K. M. H., Hátún, H., and Østerhus, S.: A stable Faroe Bank Channel overflow 1995-2015, Ocean Sci., 12, 12051220, https://doi.org/10.5194/os-12-1205-2016, 2016. 
Hansen, B., Larsen, K. M. H., Kristiansen, R., Mortensen, E., Quadfasel, D., Jochumsen, K., and Østerhus, S.: Observations from the WOW field experiment in the Western Valley 20162017 Data report, Havstovan nr. 17-03, Technical report, http: //www.hav.fo/PDF/Ritgerdir/2017/TecRep1703.pdf (last access: 8 August 2018), 2017a.

Hansen, B., Larsen, K. M. H., Quadfasel, D., and Jochumsen, K.: Historical oceanographic observations in the Western Valley Data report, Havstovan nr. 17-02, Technical report, http: //www.hav.fo/PDF/Ritgerdir/2017/TecRep1702.pdf, (last access: 8 August 2018), 2017b.

Hermann, F.: The TS diagram analysis of the water masses over the Iceland-Faroe Ridge and in the Faroe Bank Channel, Rapp. PV Reun. Cons. Int. Explor. Mer., 157, 139-149, 1967.

Jakobsen, P. K., Ribergaard, M. H., Quadfasel, D., Schmith, T., and Hughes, C. W.: Near-surface circulation in the northern North Atlantic as inferred from Lagrangian drifters: variability from the mesoscale to interannual, J. Geophys. Res.-Oceans, 108, 3251, https://doi.org/10.1029/2002JC001554, 2003.

Jochumsen, K., Moritz, M., Nunes, N., Quadfasel, D., Larsen, K. M. H., Hansen, B., Valdimarsson, H., and Jonsson, S.: Revised transport estimates of the Denmark Strait overflow, J. Geophys. Res.-Oceans, 122, 3434-3450, https://doi.org/10.1002/2017JC012803, 2017.

Knudsen, M.: Den Danske Ingolf-expedition, Bianco Lunos Kgl. Hof-Bogtrykkeri (F. Dreyer), København, 1, 21-154, 1898.

Koszalka, I., LaCasce, J. H., Andersson, M., Orvik, K. A., and Mauritzen, C.: Surface circulation in the Nordic Seas from clustered drifters, Deep-Sea Res. Pt. I, 58, 468-485, https://doi.org/10.1016/j.dsr.2011.01.007, 2011.

Nilsen, J. E., Hátún, H., Mork, K., and Valdimarsson, H.: The NISE Dataset, Faroese Fisheries Laboratory Technical Report 08-01, http://www.hav.fo/PDF/Ritgerdir/2008/TecRep0801.pdf (last access: 8 August 2018), 2008.

Nøst, O. A. and Isachsen, P. E.: The large-scale time-mean ocean circulation in the Nordic Seas and Arctic Ocean estimated from simplified dynamics, J. Mar. Res., 61, 175-210, 2003.

Olsen, S. M., Hansen, B., Østerhus, S., Quadfasel, D., and Valdimarsson, H.: Biased thermohaline exchanges with the arctic across the Iceland-Faroe Ridge in ocean climate models, Ocean Sci., 12, 545-560, https://doi.org/10.5194/os-12-5452016, 2016.

Østerhus, S., Sherwin, T., Quadfasel,D., and Hansen, B.: The overflow transport east of Iceland, Chap. 18, in: Arctic-Subarctic Ocean Fluxes: Defining the Role of the Northern Seas in Climate, edited by: Dickson, R. R., Meincke, J., and Rhines, P., Springer Science C Business Media B.V., The Netherlands, 427441, 2008
Perkins, H., Sherwin, T. J., and Hopkins, T. S.: Amplification of tidal currents by overflow on the Iceland-Faeroe Ridge, J. Phys. Oceanogr., 24, 721-735, 1994.

Perkins, H., Hopkins, T. S., Malmberg, S. A., Poulain, P. M., and Warn-Varnas, A.: Oceanographic conditions east of Iceland, J. Geophys. Res.-Oceans, 103, 21531-21542, 1998.

Pyper, B. J. and Peterman, R. M.: Comparison of methods to account for autocorrelation in correlation analyses of fish data, Can. J. Fish. Aquat. Sci., 55, 2127-2140, https://doi.org/10.1139/f98104, 1998.

Quadfasel, D.: Physical oceanography during POSEIDON cruise POS503, Institut für Meereskunde, Universität Hamburg, PANGAEA, https://doi.org/10.1594/PANGAEA.890699, 2018.

Read, J. F. and Pollard, R. T.: Water masses in the region of the Iceland-Faeroes Front, J. Phys. Oceanogr., 22, 1365-1378, 1992.

Rossby, T., Prater, M. D., and Søiland, H.: Pathways of inflow and dispersion of warm waters in the Nordic seas, J. Geophys. Res.Oceans, 114, C04011, https://doi.org/10.1029/2008JC005073, 2009.

Sabine, C. L., Feely, R. A., Gruber, N., Key, R. M., Lee, K., Bullister, J. L., Wanninkhof, R., Wong, C. S., Wallace, D. W. R., Tilbrook, B., Millero, F. J., Peng, T.-H., Kozyr, A., Ono, T., and Rios, A. F.: The oceanic sink for anthropogenic $\mathrm{CO}_{2}$, Science, 305, 367-371, 2004.

Saunders, P. M.: The dense northern overflows, Chap. 5.6, in: Ocean Circulation and Climate, edited by: Siedler, G., Church, J., and Gould, J., Academic Press, London, UK, 401-417, 2001.

Søiland, H., Prater, M. D., and Rossby, T.: Rigid topographic control of currents in the Nordic Seas, Geophys. Res. Lett., 35, L18607, https://doi.org/10.1029/2008GL034846, 2008.

Voet, G.: On the Nordic Overturning Circulation, Dissertation zur Erlangung des Doktorgrades der Naturwissenschaften im Fachbereich Geowissenschaften der Universität Hamburg, Hamburg, 98 pp., 2010.

von Storch, H.: Misuses of Statistical Analysis in Climate Research, Chap. 2, in: Analysis of Climate Variability, edited by: von Storch, H. and Navarra, A., Springer, Berlin, Heidelberg, 1126, 1999.

Whitehead, J. A.: Topographic control of oceanic flows in deep passages and straits, Rev. Geophys., 36, 423-440, 1998.

Wilkenskjeld, S. and Quadfasel, D.: Response of the GreenlandScotland overflow to changing deep water supply from the Arctic Mediterranean, Geophys. Res. Lett., 32, L21607, https://doi.org/10.1029/2005GL024140, 2005. 